Portland State University

PDXScholar

\title{
Venture Capital Dynamics: Challenges in Financing Technological Entrepreneurship
}

\author{
Evan Kaeding \\ Portland State University
}

Follow this and additional works at: https://pdxscholar.library.pdx.edu/honorstheses

\section{Let us know how access to this document benefits you.}

\section{Recommended Citation}

Kaeding, Evan, "Venture Capital Dynamics: Challenges in Financing Technological Entrepreneurship" (2016). University Honors Theses. Paper 259.

https://doi.org/10.15760/honors.244

This Thesis is brought to you for free and open access. It has been accepted for inclusion in University Honors Theses by an authorized administrator of PDXScholar. Please contact us if we can make this document more accessible: pdxscholar@pdx.edu. 
Venture Capital Dynamics: Challenges in

Financing Technological Entrepreneurship

by

\author{
Evan Kaeding \\ ekaeding@pdx.edu
}

An undergraduate honors thesis submitted in partial fulfillment of the

Requirements for the degree of

Bachelor of Science

in

University Honors

and

Business Administration: Finance

Thesis Advisor:

Sarah Tinkler

Portland State University

2016 


\section{Table of Contents}

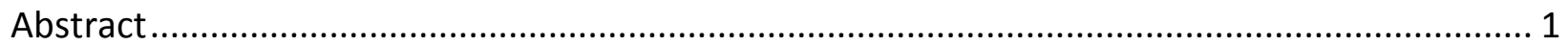

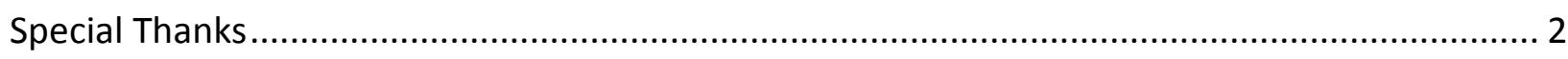

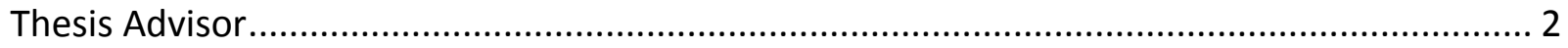

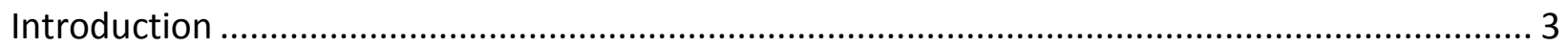

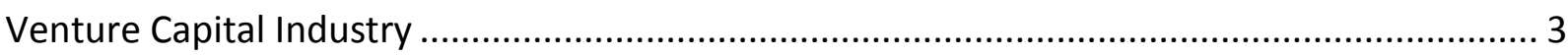

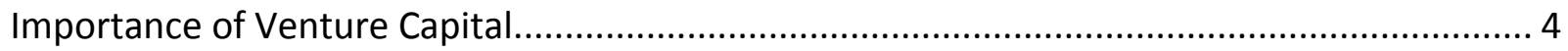

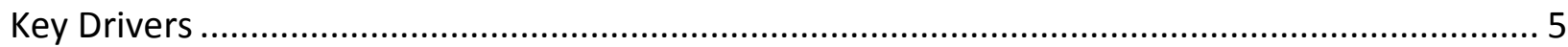

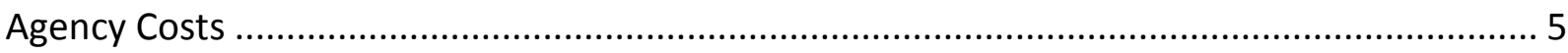

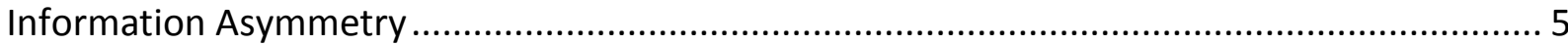

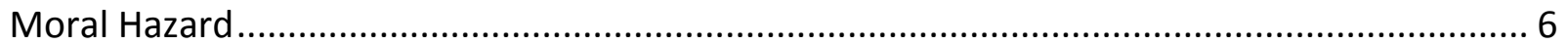

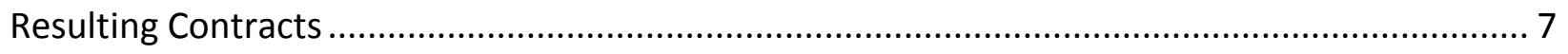

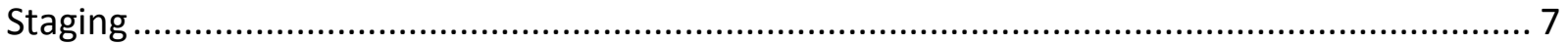

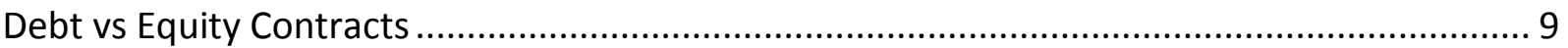

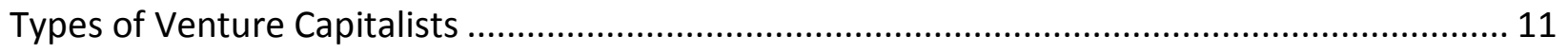

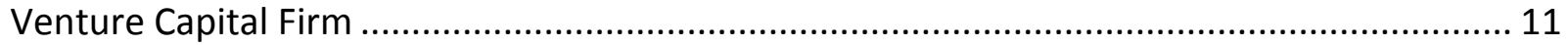

Corporate Venture Capitalist ........................................................................... 12

Signaling Among Venture Capitalists ..................................................................... 14

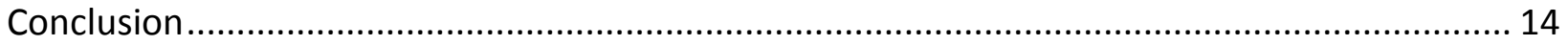

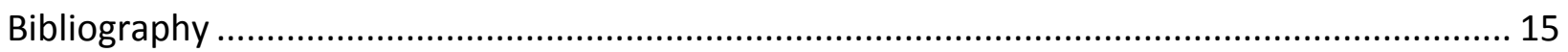

\section{Abstract}

The venture capital process is fraught with risk to the venture capitalist induced by agency costs, information asymmetry and moral hazard. Venture capitalists employ sophisticated contracting techniques to mitigate these risks, often at the expense of the entrepreneur. Additional complexity can arise depending on the affiliation of the venture capitalist. This work highlights the common pitfalls that high-technology entrepreneurs face as a result of the circumstances inherent in the fund raising process, and makes recommendations for mitigating these pitfalls. 


\section{Special Thanks}

As part of this work, I have had the privilege of interviewing several entrepreneurs who are wellacquainted with the venture capital process. Their input and feedback has been instrumental in contextualizing the academic literature surveyed for this work. As such, I would like to give special thanks to:

Colby Aley - Software Engineer at Reflect Technologies, inc.

Matt Wallington - CTO at Fanhandle

Adam Rose - CTO at TubeMogul

Karla Friede - CEO at Nvoicepay

Rick Kam - President and CoFounder at ID Experts

\section{Thesis Advisor}

Of course, this work would not have been possible without the supervision of my thesis advisor, Dr. Sarah Tinkler of the Economics Department at Portland State University. Thank you for your support and contributions. 


\section{Introduction}

The aim of this work is to demonstrate that, due to the motivations of players and incentive structures inherent in the venture capital process, entrepreneurs in high-technology businesses are highly susceptible to adverse consequences resulting from unfavorable early-stage funding agreements. While high-technology entrepreneurs tend to be technologically sophisticated with good business acumen, these skills alone are not sufficient for navigating the complexity of the dynamics at play in the venture capital process.

Fortunately, this process has received a fair amount of attention from the academic community and there is a wealth of literature that provides a basis for studying this complex series of interactions. In addition to a review of the relevant literature, this work includes commentary from industry professionals which help to contextualize academic findings.

This work is written primarily for technologically sophisticated entrepreneurs who want to understand the implications of raising venture capital before attempting to make such an effort. As this work will emphasize, the fund-raising process poses significant risks that have long term implications to the firm. Understanding these implications and identifying their associated risks is important when making the decision to raise venture capital. Hopefully, readers will find that, while these interactions are not immediately obvious to the casual observer, they are not difficult to understand when placed in their proper academic context.

\section{Venture Capital Industry}

To begin the discussion about the interactions between entrepreneurs and venture capitalists (VCs), it is important to distinguish what a VC is and what it isn't. As plainly put in William A. Sahlman's landmark work on venture capital, "Venture-capital organizations raise money from individuals and institutions for investment in early-stage businesses that offer high potential but high risk" (Sahlman, 1990). VCs are responsible for finding companies to invest in, structuring deals, managing their investments in these companies and providing a return to their investors.

The money that VCs raise is typically known as 'risk capital', or a portion of an institution's (or individual's) financial holdings that is set aside for risky investments with long maturities (National Venture Capital Association (NVCA) Yearbook, 2015). Depending on the structure of the VC firm, risk capital is subject to what is known as a 'lock-up' for durations of up to 10 years (Sahlman, 1990). Because a VC's investment in a portfolio company is considered a highly illiquid investment, long lock-up periods are necessary to generate the kinds of returns required by holders of risk capital. While there is much to say about the relationship between VCs and their investors, this work focuses on the relationship between VCs and entrepreneurs seeking capital.

The venture capital industry controls a significant amount of capital. According to the NVCA 2015 Yearbook, there are currently $803 \mathrm{VC}$ firms in the United States that manage an average of $\$ 194.9 \mathrm{M}$ each, for a total industry size of $\$ 156.5 \mathrm{~B}$. While the amount of capital currently under 
management is higher than the recorded average, it is still below the peak that was reached in 2006. Interestingly enough, the value of investments made by venture capital companies is still only roughly half the peak reached in the year 2000 just prior to the dot-com bust.

Approximately $72 \%$ of venture capital investments in 2014 went to information technology companies, with medical companies receiving 18\%, and all other industries receiving the remaining share of investments.

\section{Importance of Venture Capital}

The venture capital industry is unique in the sense that it acts as funding mechanism for highrisk, early-stage companies. Economically speaking, it is responsible for allocating risk capital to risky investments, the kind of investments which are not generally undertaken by institutional investors or banks. Because of the low appetite for risk among institutional investors and lenders, entrepreneurs of high-technology companies are limited in their choice of capital sources.

One of the most significant challenges young high-technology firms face are financial constraints (Colombo, Massimo and Grilli, 2007). Financial constraints are characterized by a lack of funds to pursue or maintain profitable projects within a firm. Put simply, a company that may have a clear competitive advantage and customer value proposition may not be able to execute its mission to its fullest extent because of undercapitalization.

This problem is especially acute in high-technology companies. These firms typically begin with a high-cost research and development process (Zarzecki, 2011). While firms are busy deploying resources to construct a product or service, they typically will not have revenue and need to rely on startup capital (often contributed by founders) for basic functions like office supplies and rent.

To alleviate these financial constraints, young firms have a limited number of options. Banks are unlikely to lend to organizations in their early stages due to a lack of operating history and a lack of collateral (Carpenter and Petersen, 2002). Furthermore, a firm that faces stiff competition from rivals competing in the same space faces even higher barriers to raising capital as competitive market pressures push the probability of successful loan repayments down.

In the absence of bank loans and institutional grade investment capital, young firms can alleviate these financial constraints by taking on venture capital investments (Bertoni, Croce, and Guerini, 2015). In an empirical analysis of 128 VC-backed firms and 233 non-VC-backed firms, Bertoni et al. found that a single round of funding was necessary, but not sufficient, to lower or alleviate the financial constraints of growing technology companies. Because of this inherent match between the demanders of risk capital and suppliers of risk capital, a market is created.

While VCs are known to provide the tangible benefit of capital, there are several intangible benefits that VCs are thought to provide to the companies in which they invest as well. Most models assume that VCs are able to contribute by offering managerial advice to the company on a periodic basis. Additionally, VCs that are highly specialized in a particular industry may have the 
ability to help with talent acquisition and other early-stage business challenges. The importance of these intangible contributions by VCs are emphasized in later sections.

\section{Key Drivers}

The academic study of venture capital has identified several concepts that play pivotal roles in the venture capital process. While some of these concepts exist independently in the world of business, their interaction, as this work will demonstrate, can lead to adverse funding agreements for entrepreneurs of high-technology ventures. These funding agreements can be adverse for entrepreneurs in the sense that they cause the entrepreneur to receive an inefficient level of investment or lose control of their business entirely.

Agency Costs

Agency costs are a widely researched phenomenon in finance. They constitute the costs associated with having an agent act on behalf of a principal. This relationship is inherent between VCs and entrepreneurs given that the entrepreneur is tasked with managing the capital invested by a VC. The costs associated with agency often arise when the party in control of the funds (the entrepreneur in this case) makes decisions that are not in the best interest of the owner (venture capitalist in this case) of the funds. As this work will demonstrate in a later section, a VC's desire to minimize agency costs heavily influence the nature of the funding agreement.

It is important to note that agency costs have an indirect influence on the nature of the funding agreement between an entrepreneur and a VC as well. As previously noted, venture capitalists are responsible for managing the risk capital of their investors. Because of the nature of this relationship, investors are subject to not only the agency costs between themselves and the VC, but also the costs between a VC and an entrepreneur. While an examination of the structural nature of the agreement between a VC and investor is beyond the scope of this work, Sahlman (1990) notes that "venture capitalists have many opportunities to take advantage of the people who invest with them". In an effort to reduce these specific agency costs, investors ensure that strict contracts be implemented between themselves and the VC.

The resulting contractual link between the entrepreneur and investor has been shown to influence the nature of the agreement between the VC and entrepreneur (Andrieu, Guillaume, and Groh, 2012). As a result, it is important for entrepreneurs to consider both the manager of funds (venture capitalist) and source of funds (investor) when selecting a funding partner. A later section of this work deals specifically with these concerns.

\section{Information Asymmetry}

Information asymmetry is a concept in economics that deals with transactions in which one party has more information than the other. In a market with high information asymmetry, buyers are 
unable to distinguish the quality of goods among sellers. Because buyers know that only a fraction of the goods are of high quality, they price the risk of purchasing a product of lesser quality into their valuation of the good. Sellers of high quality goods are thus incentivized to leave the market, being unable to receive full price for their goods, leaving only low quality goods available for sale (Akerlof, 1970). This leads to an adverse selection problem that can lead to a collapse in a given market. The implications of information asymmetry are important to understanding the dynamics in the venture capital funding process.

The above description of market failure demonstrates the inherent problem that exists in markets with high information asymmetry. Entrepreneurs have firms that vary in quality, but the quality is generally only known by the entrepreneur. A VC, in accounting for the fact that many firms may not be of high quality, is likely to discount the valuation of the company. This phenomenon drives entrepreneurs with highly valuable companies from the market and leaves only low-quality firms in which VCs can invest.

As with agency costs, information asymmetry plagues VCs on both sides of their organization. VC firms face a tiered form of information asymmetry, which stems from the entrepreneurs themselves and must be mitigated by self-serving investors (Sahlman, 1990). It is assumed that an entrepreneur will have a significantly higher amount of information regarding their own business than a VC, for they are the ones responsible for operating it on a day-to-day business. Following this assumption, an entrepreneur will have a better idea of the business-specific risks associated with their venture than a VC does.

An important distinction must be made between business-specific risk and industry or sectorspecific risk. VCs that are well-versed in their industries are likely to have information that may not be known to the entrepreneur. However, limitation of knowledge about business-specific risks relative to that of the entrepreneur limits a VC's ability to accurately gauge the quality of the investment opportunity.

Another implication of this information barrier is that access to debt capital from traditional financial institutions is often significantly impaired (Carpenter and Peterson, 2002). While businesses that are well-established, have significant collateral assets and a long-operating history may have an easy time obtaining debt financing, a small, high-technology startup is likely to find that the cost of debt financing is too high. This then pushes them toward raising money through by selling equity or by contributing personal-owner capital (Colombo, Massimo, and Grilli, 2007).

\section{Moral Hazard}

This concept describes a situation in which a party is involved in a transaction with a high level of risk (such as a venture capital investment) but is protected from the downside loss associated with that risk, which is generally born by another party. Moral hazard in the context of venture capital describes a situation in which the downside risk of a VC is greater than that of an entrepreneur who is given control of the funds. Because of information asymmetry, it is difficult 
for a VC to determine whether the company actually intends to provide a positive return to the VC. While information asymmetry describes an entrepreneur's ability to return these funds, moral hazard describes the intent of the entrepreneur.

Moral hazard is generally factored into theoretical models when studies attempt to determine optimal contract or VC portfolio allocations. As Kanniainen, Vesa and Keuschnigg (2003) note in their theoretical model, moral hazard on the part of the entrepreneur must be accounted for when determining the optimal portfolio size of a VC due to the diminishing return to managerial advice provided by the VC. As fund size increases, managerial advice of the VC, assumed to be a limited resource, is spread thin among portfolio companies, and the incentive for an individual entrepreneur to make good on their obligation falls accordingly. This effect is known to produce double moral hazard, whereby an entrepreneur may not get the managerial advice or mentorship that was originally promised by the VC.

\section{Resulting Contracts}

In light of all of these pitfalls to the VC, one might ask, what is a VC to do if they want to reduce their downside risk while still providing an incentive to an entrepreneur? Intelligent VCs have developed best practices that are now common in the industry that help them achieve the goals set by their investors. This section discusses ways that VCs can reduce the risk of their investments, sometimes at the expense of the entrepreneur.

\section{Staging}

Staged capital investments result in a process whereby a VC commits to a certain level of investment in exchange for a fixed amount of equity. This transaction is comprised of multiple smaller investments spread out over time after the successive achievement of predefined financial or operational benchmarks. Staging is one of "the most potent control mechanisms a venture capitalist can employ" (Gompers, Alan and Lerner, 2004).

Some entrepreneurs that are new to the funding process believe VC funding is a one-time transaction in which capital and equity are exchanged in the agreed-upon amounts and the entrepreneur is free to run their business as usual. The reality is that, before an entrepreneur can receive a funding commitment from a VC, it is very likely that the two parties will agree upon a certain set of financial or operational benchmarks that the company must meet. Their ability to meet these benchmarks will determine the frequency and amount of subsequent capital infusions. Another potent aspect of this funding mechanism is that the VC usually reserves the right to abandon the investment altogether if they receive information through their monitoring process that reflects poorly upon the firm.

After examining the pitfalls to the $V C$ in the previous section, it seems logical that a self-interested party would insist on a staged funding process. The benefits to the VC are numerous, and are described in detail below: 


\section{Mitigation of Agency Costs}

Staging helps VCs mitigate agency costs by ensuring that entrepreneurs meet benchmarks that improve the tangibility of the firm's assets (Gompers, Alan and Lerner, 2004). By ensuring that entrepreneurs invest in areas which are sure to deliver value to the firm, VCs thus reduce agency costs since their correlation with the tangibility of firm assets is negative.

Gompers et al. also note that, because a VC is typically responsible for managing investments in multiple companies, monitoring the results of these companies is costly and cannot be done continuously. By making successive investments contingent upon the achievement of previouslydefined benchmarks, the VC can ensure that measurable progress is the primary criterion for an investment decision.

A clarifying note to make is that VCs, while they are typically primary investors in a company, do not typically have much managerial control over the company (Sahlman, 1990). Unless the entrepreneur has given up a board seat in exchange for the investment, the direct control a VC has over a firm is generally limited. Thus, preserving the power to grant or deny access to funding provides the VC significantly more influence over the portfolio company than could otherwise be exerted.

\section{Lowering the Barrier to Information Symmetry}

Another key benefit of staging investments is the ability of the VC to learn more about the company through the monitoring process. Gompers et al. random sample of 794 VC-backed companies confirm this notion by showing how VC firms exercise the right to abandon if they learn negative information about a firm. This allows them to preserve capital for other investments that may be more lucrative for the VC.

\section{Optimal Efficiency}

Some studies suggest that deploying capital infusions in tranches maximizes efficiency for both the entrepreneur and the VC (Dahiya, Sandeep, and Ray, 2012). Dahiya et al. show using a theoretical model how a VC benefits from the ability to more accurately assess the value of an investment after continued monitoring.

The benefit of staging to the entrepreneur is more subtle. In their model, Dahiya et al. account for the level of information between the entrepreneur and the VC. What they also include is the way in which the cost of capital for the entrepreneur is influenced by their relative performance against the pre-defined benchmarks they are contractually bound to. What they find is that when an entrepreneur meets their benchmarks successfully, it provides a reduction in their cost of equity capital. In other words, the entrepreneur has to give up less equity for the same amount of money in successive rounds of financing.

Other studies discuss the interaction effects between multiple VCs and how the staging process provides a track record that firms can use to help establish credibility, encouraging further investment from other VCs in later rounds. A later section of this work will discuss the interaction between VCs in successive rounds. 


\section{Pitfalls of Staging to the Entrepreneur}

While many academic studies highlight pitfalls to the VC, few seem to address the hazards that the entrepreneur faces in the fund-raising environment. As a part of this work, interviews were conducted with several industry professionals who had a key role in the organization at the time that a venture capital investment was received. Some their most salient points are outlined in this section.

Matt Wallington, a Portland-based technologist and entrepreneur who has successfully raised several seed rounds, emphasized the importance of establishing meaningful benchmarks in the staging process. Benchmarks should be closely linked to economic value creation so as not to distort incentives or encourage excessive risk-taking. Furthermore, he places emphasis on ensuring that benchmarks are reasonably attainable for the entrepreneur in the allotted time frame, warning that some VCs gravitate toward grandiose benchmarks that stretch the resources of the firm too thin and subsequently reduce the effort-reward ratio of the entrepreneur.

An example of arbitrary benchmarks that Matt cited included tying funding to 'user counts' or the number of users on a particular software service or platform. While this is a closely tracked metric in the valuation of both public and private software companies, it fails to take into account an often egregious cost of user acquisition that may actually lead to the destruction of shareholder value. If an entrepreneur has incentives to steer a company toward one operational metric, certain compromises may be made elsewhere in reaching that goal.

Rick Kam, the founder and president of a Portland-based information security company ID Experts, was quick to point out that entrepreneurs who ask for too much money in early rounds risk jeopardizing their ability to raise funds in the future. By relinquishing too large a portion of equity to a VC or angel in early stages, there is a diminishing amount of equity left to sell that commands a lower valuation if the company finds itself in need of more venture capital. Rick instead suggests that more frequent, smaller rounds are advantageous and can lower the cost of capital between rounds if the firm is able to meet the pre-determined benchmarks.

\section{Debt vs Equity Contracts}

The confluence of agency costs, information asymmetry and moral hazard directly influence the type of funding agreement that is preferable to both parties. The determination of optimal contracts between a VC and entrepreneur is a well-studied process. Several empirical and theoretical studies suggest that convertible securities, contracts containing elements of both debt and equity, are an effective way to mitigate the divergent incentive structures inherent in the venture capital process. While these contracts offer VCs a way to mitigate risks inherent in the funding process, some of the provisions in these deals can have drastic consequences if not property negotiated.

\section{Convertible Securities}

Convertible securities are used in venture capital finance because their flexibility allows entrepreneurs and VCs to tailor the contract transaction in a way in which the incentives of both 
parties are well-aligned. While there is generally no "standard" convertible security used for these types of arrangements, empirical studies suggest that there are some commonalities among VC investment deals that are unique to the funding process.

Generally speaking, a convertible security is a loan granted by a VC to an entrepreneur's company that has defined terms for payback. At the maturity of the loan, the VC can elect to receive either the debt repayment including all accrued interest, or exercise a conversion option that alleviates the debt burden of the entrepreneur's company and gives the VC a claim on the equity in the firm.

Analyzing the incentives of the two parties clearly illustrates the preference of the VC toward this kind of contract, compared to a simple debt or equity contract. This is valuable to a VC because it allows them the option to determine at a later date whether it is advantageous to take an equity position in the company. In the time between the origination of the security and the period at which a VC can exercise their option, the information asymmetry between the two parties is likely to have been dramatically reduced through the monitoring efforts of the VC. Furthermore, the entrepreneur has a strong incentive to invest money wisely by accumulating valuable company resources to avoid a significant debt repayment. The incentive of the entrepreneur to defer private consumption through business expenditures (ex. Company jets and flashy marketing campaigns) using the VC funds is an example of a way that this contract can be used to minimize agency costs.

Klaus Schmidt (2003) argues that, due to the double moral hazard inherent in venture capital investments, convertible securities incentivize both parties to invest efficiently in the firm. Schmidt is quick to point out that, while the entrepreneur is typically protected by limited personal liability, a large debt repayment could cause an entrepreneur to lose control over the firm's finances.

Another earlier empirical model designed by Admati and Pfleiderer (1994) counters the previously held notion that the type of securities offered by the entrepreneur are fully revealing about the performance and expectations of the firm. While this model does not take into account the VC's cost of monitoring investments, it does demonstrate that information asymmetries between the entrepreneur and VC provide nearly insurmountable hurdles to optimal investment levels, which can lead to market failure.

Kaplan and Stomberg (2003) analyzed a sample of 213 investments made by 14 VCs. While this sample may not fully represent the ecosystem of VC investments, it offers some insights that are valuable in ascertaining how VCs use these contracts to mitigate risk. Of the 213 investments made by VCs, 206 of them involved the use of some form of convertible securities, with 170 investments involving only convertible preferred stock. Prominent parts in these contracts include the rights of VCs to control cash flow rights and liquidation controls in the event that the company becomes subject to a large debt repayment. These rights are typically dependent on 
the performance of the firm, with better performing firms sacrificing fewer rights with increased performance.

\section{Extra Provisions}

These funding agreements also feature a number of extra provisions that encourage strong performance by the entrepreneur. Kaplan and Stomberg (2003) find wide use of automatic conversion rights used to incentivize entrepreneurs to meet or exceed expectations. These are often tied to firm performance, whereby an entrepreneur can essentially force a VC to exchange their claim on the firm as a creditor for a pre-determined equity stake.

Also found in the study are provisions that raise the cost of leaving the firm to an entrepreneur. These provisions include vesting schedules, whereby entrepreneurs' equity in the firm is only slowly re-allocated to them at the passage of certain performance milestones, and non-compete clauses that legally prohibit the entrepreneur from leaving and working for a competitor. These provisions are designed to reduce the risk of the VC, but can often have a significant negative effect on the entrepreneur in the event of business failure that extends beyond their implicit limited liability.

Additionally, clauses changing the composition of the board of portfolio companies are somewhat common in this sample. $18 \%$ of cases had language that tied VC control of the board to firm performance. Approximately $41 \%$ of the sample permitted VCs to have an outright voting majority on the board.

\section{Types of Venture Capitalists}

The previous section documented ways that VCs can reduce their risk when faced with the task of allocating risk capital to illiquid, highly uncertain investments, while preserving their own interests. This section examines some of the specific incentives of VCs and how they may differ depending on the nature of their investors. Intuitively, these differences cause variations in the incentives of the VC, which influence the funding process in a variety of ways.

To this point, this work has discussed "VCs" as if they are a single homogenous group of managers of risk capital with identical incentive structures and no variance in the quality or form of managerial advice (see 'Traditional Venture Capitalists' below). While this assumption is convenient for analyzing the complex interactions among agents, actual discussions and transactions are more specifically tailored to the style of a particular VC.

\section{Venture Capital Firm}

Traditional venture capital firms are organized to provide investment returns to owners of risk capital over a long period of time. Many studies have highlighted the intricacies of these entities and provided extensive supporting documentation. For the purposes of this work, traditional VCs will be analyzed inasmuch as their structure influences their investment decisions on a very high level. 
Gompers, Alan and Lerner (2004) point out that VC firms are typically organized as limited partnerships, with investors assuming the role of limited partners (LP) and VCs assuming the role of general partners (GP). The original partnership agreement dictates the compensation structure of the VC, the duration that the VC will have control over the LP's funds, and the covenants that limit a VCs autonomy over the funds. These agreements typically last for the lifetime of the fund and are difficult to change once fully ratified.

Sahlman (1990) notes in his work concerning the structure of VC firms that LPs generally use compensation systems that are directly linked to value creation. Of the firms surveyed by Venture Economics, an annual management fee of $2.5 \%$ of assets under management was found in more than $50 \%$ of these firms. These fees are typically used to cover the costs of basic operations. To incentivize VCs to perform well, $88 \%$ of firms entitled VCs to $20 \%$ of the realized gains in the fund over its lifetime. Gompers et al. suggest that these specific percentages are subject to change over time and most affected by changes in the supply of and demand for risk capital.

Importantly, these firms' primary function is to deliver a monetary return to owners of risk capital, and the incentive structures they employ encourage behavior to this end. However, other sources of risk capital have incentives and subsequent structures that are different from those of the traditional VC.

\section{Corporate Venture Capitalist}

Corporate Venture Capitalists (Corporate VCs) are managers of risk capital that invest with different incentives than traditional VCs (Chesbrough, 2002). In the case of the corporate VC, the risk capital that is being managed is owned by the parent corporation. Earlier theoretical literature suggested that corporations were ineffective at operating as VCs due to ineffective incentives for fund managers and rigid organizational structure. However, empirical research conducted by Gompers and Lerner (2000) indicate that corporate VC investments appear to be "at least as successful" as those backed by individual venture organizations.

This is not to say that these corporate VCs are inherently better than traditional VC firms, or that engaging with one is not without its risks. Gompers and Lerner note that the stability of these funds is questionable, with their empirical results indicating that many corporate VC firms cease operations after just a small number of investments.

While some organizations operate a VC portfolio whose function is merely to provide financial returns to the company, others are organized to give the parent corporation some form of strategic benefit from the investments they make.

Chesbrough (2002) identifies two dimensions along which corporate VCs can be evaluated: the investment objective and the degree to which portfolio firms' operations are linked to those of the parent firm. These two dimensions form the basis for a rough classification of corporate VCs. These are factors that entrepreneurs should consider when raising funds through a corporate 
VCs, as the incentives of these four different strategies will play a role in determining the future of the portfolio companies in which they invest.

\section{Driving Investments}

Chesbrough (2002) explains that corporate VCs with a driving investment strategy have a strategic objective set by the parent company and invest in companies whose operational capabilities are similar to those of the parent company. The example used in his work is Microsoft's investment into firms that utilize its. Net architecture, as a way to advance its architecture and promote the adoption of its standards.

One significant advantage to the entrepreneur of transacting with this kind of VC is that they tend to value companies at a premium compared to traditional VCs (Gompers and Lerner, 2000). Because there is a close link between the operational capabilities of the corporation and the portfolio company, the value of the synergies between the two makes the investment more attractive to a corporate VC.

A drawback to engaging with a corporate VC employing a driving strategy is the tendency for milestones and objectives for the entrepreneur to be tied to objectives that are set with the parent corporation's best interest first. While discussion about the portfolio company's strategic focus would normally be concerned with maximizing the value of the VC's investment, the parent corporation's strategy is likely to have a significant influence on this process, especially if the entrepreneur has exchanged board seats for investment capital.

\section{Enabling Investments}

These kinds of corporate VCs have strategic corporate objectives but invest in companies with a loose tie to the parent corporation's operational capabilities. Corporations engage in this type of VC strategy because it allows them to identify and control compliments to their existing business. The classic example of a corporate VC known for making enabling investments is Intel Capital. Intel Capital's investment strategy focuses on identifying mature startups whose products and services make use of Intel microprocessors.

Of all of the corporate VC types, this is likely the best for entrepreneurs of high-technology companies. Because the corporate VC is not focused solely on deriving a financial return on its investment, the entrepreneur has more flexibility in determining the optimal allocation of VC funds without the pressure of a quick turnaround. Furthermore, the entrepreneur has a better chance of maintaining strategic autonomy, so long as the products and services the firm produces continue to add value to the corporate VC.

\section{Emergent Investments}

VCs who have an emergent investment strategy often are focused on deriving a financial return and invest in companies with close ties to the firm's core operations. In this situation, corporate VCs see their ability to add value to a portfolio firm as a way to generate a return on their investment. By investing in firms with operations closely linked to that of the parent corporation, 
the corporate VC can impart industry knowledge, experience, and managerial advice that has the ability to significantly enhance the value of the investment.

\section{Passive Investments}

Firms engaging in passive investments are seeking a financial return and invest in companies without a close link to the parent corporation's operations. As a result, a firm employing this strategy is in a similar position to that of an LP in a traditional VC firm. While these kinds of investment strategies were popular among firms due to value created through diversification, the understanding of modern portfolio theory has pushed many firms away from it. In his article, Chesbrough (2002) offers a convincing argument that corporations should specialize their investments, since modern portfolio theory indicates that investors can achieve investment diversification through their own portfolio allocations.

\section{Signaling Among Venture Capitalists}

An important consideration that must be made when raising capital is that VCs are likely to interact with one another when a company is raising future rounds. If, for example, a VC that participated in an initial round is either unable or unwilling to participate in a follow-on round, it sends a negative signal to the VC community.

Adam Rose emphasized in our discussion that the first VC a firm takes investment from is important in determining the success of future rounds. He indicated that having an investor that was both able and willing to participate in follow-on rounds was important in signaling to outside VCs.

Karla Friede indicated that an advantage of partnering with successful early stage VC firms is the ability to get favorable introductions to firms that participate in larger funding rounds. She noted that firms that place significant VC investments typically source deals from smaller VCs who have had good success with their investments.

\section{Conclusion}

By closely examining the nature of the relationship and differing incentives of an entrepreneur and a VC, this work shows that there are a number of risks inherent in the fund raising process for both parties. These risks can be primarily attributed to the confluence of agency costs, information asymmetry and moral hazard. An analysis of the contracts that result from these intricacies demonstrates some methods and techniques that VCs employ to transfer their downside risk to the entrepreneur.

One of the key takeaways from this work is that the exercise of defining and setting performance benchmarks is crucially important to the success of the firm. As previously discussed, an arbitrary benchmark can distract the entrepreneur from activities that truly add value to the business. 
It is also imperative that entrepreneurs not ask for too much money in early rounds. If the company needs to raise additional funds in the future, there should be enough equity left in the business to still incentivize the entrepreneur to maintain his or her effort level.

Furthermore, this work provides evidence that the affiliation of the VC is important in determining how the incentives of a VC influence the nature of the funding agreement. As an entrepreneur, it is always important to carefully consider the parties with whom partnerships are structured. This work highlights some of the pitfalls associated with the fundraising process, but does little to provide methods or techniques to overcome them. Mitigation of these challenges is difficult, but their explicit identification should offer entrepreneurs the ability to creatively formulate solutions that are specific to their business. In negotiations, VCs are not keen to vocalize these concerns, but going into a funding agreement with an understanding of the operating parameters will prove invaluable.

While the recommendations made by this work are based on theory and experienced provided by academics and practitioners respectively, there are limitations to its use. First and most notably, the primary sources for this work (interviews) are with practitioners based on the West Coast of the United States, and may not accurately represent the global venture capital climate. Additionally, much of the research cited has been completed within the last 25 years. It is likely that there have been shifts in the structure of the industry in light of the dot-com bust in the early 2000's and The Great Recession.

Topics for future study are numerous. A significant element in many of the theoretical models cited in this work include the cost of monitoring for a VC, which has a diminishing return to scale as portfolio size increases. With the technological changes that have occurred in the past 25 years, it is likely that the cost of monitoring investments has fallen dramatically. Seeing if these monitoring costs have actually been reduced and if there is an effect on VC investment would yield interesting conclusions. Along this same vein, an inquisition into the value of managerial advice provided by VCs is warranted given the small amount of empirical information on this topic. Additionally, it would be interesting to examine the veracity of these conclusions on an international basis.

\section{Bibliography}

Admati, Anat R., and Paul Pfleiderer. "Robust financial contracting and the role of venture capitalists." The Journal of Finance 49, no. 2 (1994): 371-402.

Akerlof, George. The market for "Iemons": Quality uncertainty and the market mechanism. Macmillan Education UK, 1995.

Aley, Colby. Interview by Evan Kaeding. In-person Interview. Heart Coffee, 3/5/2016 
Andrieu, Guillaume, and Alexander Peter Groh. "Entrepreneurs' financing choice between independent and bank-affiliated venture capital firms." Journal of Corporate Finance 18, no. 5 (2012): 1143-1167.

Bertoni, Fabio, Annalisa Croce, and Massimiliano Guerini. "Venture capital and the investment curve of young high-tech companies." Journal of Corporate Finance 35 (2015): 159-176.

Carpenter, Robert E., and Bruce C. Petersen. "Capital market imperfections, high-tech investment, and new equity financing." The Economic Journal 112, no. 477 (2002): F54-F72.

Chesbrough, Henry W. "Making sense of corporate venture capital." Harvard business review 80, no. 3 (2002): 90-99.

Colombo, Massimo G., and Luca Grilli. "Funding gaps? Access to bank loans by high-tech startups." Small Business Economics 29, no. 1-2 (2007): 25-46.

Dahiya, Sandeep, and Korok Ray. "Staged investments in entrepreneurial financing." Journal of Corporate Finance 18, no. 5 (2012): 1193-1216.

Friede, Karla. Interviewed by Evan Kaeding. In-person Interview. Nvoicepay Office, 5/5/2016

Gompers, Paul Alan, and Joshua Lerner. The venture capital cycle. MIT press, 2004.

Kam, Rick. Interview by Evan Kaeding. In-person Interview. Kam residence, 5/6/2016

Kanniainen, Vesa, and Christian Keuschnigg. "The optimal portfolio of start-up firms in venture capital finance." Journal of Corporate Finance 9, no. 5 (2003): 521-534.

Kaplan, Steven N., and Per Strömberg. "Financial contracting theory meets the real world: An empirical analysis of venture capital contracts." The Review of Economic Studies 70, no. 2 (2003): 281-315.

National Venture Capital Association (NVCA) Yearbook. Thompson Reuters, 2015.

Rose, Adam. Interviewed by Evan Kaeding. Skype Call. 4/25/2016

Sahlman, William A. "The structure and governance of venture-capital organizations." Journal of financial economics 27, no. 2 (1990): 473-521.

Schmidt, Klaus M. "Convertible securities and venture capital finance." The Journal of Finance 58, no. 3 (2003): 1139-1166.

Wallington, Matt. Interview by Evan Kaeding. In-person Interview. Case Study Coffee, $4 / 20 / 2016$

Zarzecki, Dariusz. "Valuing Internet Companies. Selected Issues." Folia Oeconomica Stetinensia 9, no. 1 (2010): 105-120. 